\title{
A study of the acoustics and speech intelligibility quality of mosques in Malaysia
}

\begin{abstract}
This study presents the assessment of the quality of speech intelligibility of two Malaysian mosques and the results are used to develop a set of general acoustical guidelines to be used in the design of a mosque. Two mosques were selected for the research: Masjid UPM and the Masjid Jamek. The objective of the research is to enable the comparison of the acoustics and speech intelligibility between the mosques as function of the size, volume, occupancy and other parameters of the main prayer hall on the acoustic and speech intelligibility of the respective mosques. The reverberation time (RT60), speech level (SL), background noise $(\mathrm{BN})$, signal-to-noise ratio ( $\mathrm{S} / \mathrm{N}$ ratio) were determined and are used to develop the speech transmission index (STI) and rapid transmission index (RASTI) prediction models for both mosques. It was observed from the results that the RT60, STI and RASTI values shows better performance over number of occupancy for both mosques. Furthermore, the BN and SL results were visualized using the spatial distribution patterns (SDP) of the main hall. The results of the analysis show that the overall acoustic and speech quality of Masjid Jamek is better when compared to the overall acoustic and speech quality of Masjid UPM. These results are then used to develop a set of design recommendations to ensure adequate speech intelligibility quality a mosque.
\end{abstract}

Keyword: Mosque acoustic; Speech intelligibility 